\title{
Environmentalism and sustainable development from the point of view of tourism
}

\author{
Z. Baros ${ }^{1}$ \& L. Dávid ${ }^{2}$ \\ ${ }^{I}$ Department of Regional and Rural Development, \\ Károly Róbert College, Gyöngyös, Hungary \\ ${ }^{2}$ Department of Tourism and Regional Development, \\ Károly Róbert College, Gyöngyös, Hungary
}

\begin{abstract}
As a consequence of the rapid growth of the tourism sector, special emphasis is placed on destinations and tourism products connected to or based on certain physical and environmental factors. However, the negative environmental consequences of tourism are, in many cases, overemphasised to the social and/or economic elements of sustainable development. Thus, it is important to find an adequate balance of the elements mentioned above within tourism development in order to achieve an optimal way of fulfilling all requirements of sustainable development. In order to do this, a potential method is introduced by applying the Sustainability Value Map, developed originally for buildings and urban development projects, to the evaluation of sustainable tourism products. This method gives rise to further questions concerning the selection of the right set of indicators and the importance of local or regional issues. Using it as a tool, it may promote the process of holistic tourism planning and development.

Keywords: environmentalism, sustainable tourism, environmental impacts, Sustainability Value Map.
\end{abstract}

\section{Introduction - sustainability in tourism and its aspects}

The term 'sustainable development', in the last decade of the $20^{\text {th }}$ century, became widely used by governments, non-governmental organisations, the private sector and academia. Although, sustainable development is associated by many with issues like energy use, pollution and waste, they are now recognised as certain elements of sustainability, and the concept addresses three equally important issues: environment, economy and society [1]. 
The concept has been applied in the tourism sector in various ways of which one gives the following definition of sustainable tourism: 'meeting the needs of present tourists and hosts while protecting and enhancing opportunities for the future'. Thus, sustainability in the context of tourism means regulating the use of tourist resources so that they are not consumed, depleted or polluted in such a way as to be unavailable for the use by future generations of tourists [2]. This form of sustainable tourism, oriented toward the viability of tourism industry, is referred to as the 'economic sustainability of tourism' or 'tourism imperative' [1]. In order to achieve this, the primary aim of tourism development is satisfying the needs of tourists and other players in the industry.

As the public has become aware of the extent of human impact on natural systems, environmental issues began to gain more ascendancy by the late 1960s and also with the rapid growth in tourism experienced in the second half of the $20^{\text {th }}$ century, concerns grew about the physical environments of destinations used for tourism. The reliance of tourism upon the natural resources of the environment and the fact that its development induces changes which can be negative were realised. Accompanying the heightened awareness of environmental problems was also a realisation that the environment and development are inexorably linked. Development cannot take place upon a deteriorating environmental resource base neither can environment be protected when development excludes the costs of its destruction. In some cases, the environmental resources of tourism receive consideration, but are secondary to the growth of the tourism sector ('product-led tourism'). A third concept called 'environmentally led tourism' can also be mentioned where types of tourism would be promoted that are reliant upon a high-quality environment [1].

Several forms of tourism were assumed to be 'appropriate/responsible' causing the least change to the tourist resource and the most likely to be sustainable, e.g. natural area tourism including a number of activities such as hiking, mountain-climbing, fishing, hunting, camping, etc. However, there is wide scepticism about the long-term sustainability of these.

\section{Destination and the physical environment}

\subsection{The role of place}

The attractiveness of a given tourist destination implies the state of the physical environment, thus the variety of activities and the resultant cognition as shown in figure 1. Most tourism products and destinations are connected to certain physical and environmental factors therefore any changes in these may lead to a decrease in the popularity of and the demand for the given product as well as maintaining the quality of the product may be a special challenge for the tourism sector [3]. In some cases, such as the case for outdoor tourism activities based on the attractions of the physical environment, the basis for the product itself (the system of physical environment) can be degraded and destructed to an extremely high degree. 


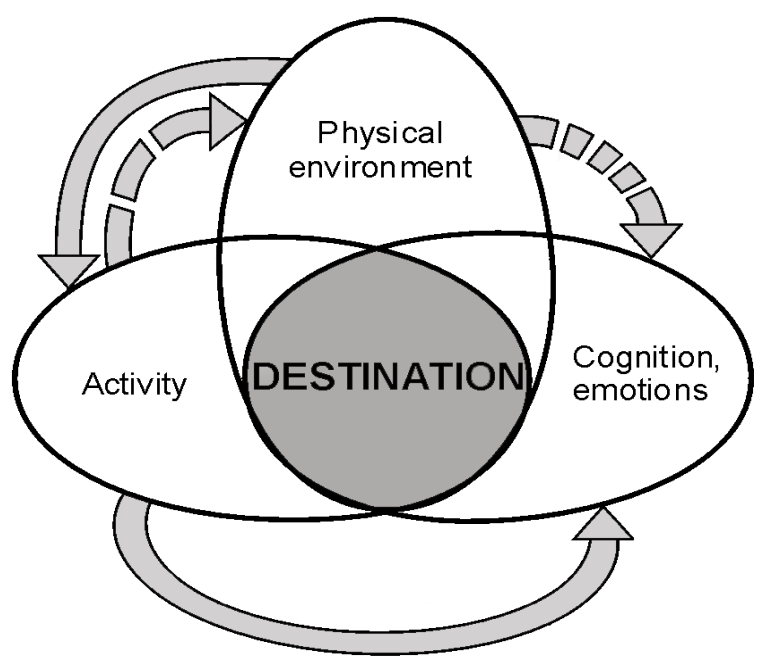

Figure 1: The main factors of selection of destinations, modified after Dávid et al [4].

The most popular locations for (activity-based) tourism are usually the most susceptible (coastal and mountain areas) ones, too. Sustainability has become a focal point of interest especially in areas which, in the future, will become more susceptible or more popular destinations and as such, the increasing number of visitors (i.e. the higher level of crowdedness) will result in more serious of environmental impacts.

The development of tourism requires physical resources to facilitate its expansion. Maintaining the quality of the environment, however, is usually also among the main goals of sustainable tourism as set up by various authors. Despite the confusion about what is meant to be an environmentally 'responsible' approach to tourism development, it is apparent that the protection of the natural resources upon which tourism is based is essential for the sustainable development of a location [5]. It is also important to realise that sustainable development is not concerned with the preservation of the physical environment but with its development based on sustainable principles of which environment is only one.

\subsection{The relevance of environmental impacts of tourism}

With increasing numbers of people visiting a spatially diminishing and continually degraded natural world there is much scope for negative impact [6]. The negative environmental consequences of tourism include resource usage (land, water, etc.), human behaviour towards the destination environment and pollution (water, noise, air and aesthetic). The impacts of tourism and recreation on the physical environment (interaction of humans with their environment) are important because of the sheer significance of the physical environment for the 
recreation and tourism industry. In the absence of an attractive environment, there would be little tourism [7]. Tourism in natural areas impacts upon the natural environment in either positive or negative ways; it also has many social and economic consequences. Clearly, there are also social and economic impacts associated with recreational activity and tourism development [6].

It is often disregarded, however, that impact significance can depend on the type and source of impact (diversity, intensity and duration of the activities), environmental sensitivity (location), other cumulative pressures and the effectiveness of any management that is in place. Mountain environments are susceptible to disturbance due to steep slopes and thin soils and this is especially so in the high rainfall environments that span the tropics [8].

It is important to detect the effects of tourism on all aspects of an ecosystem as well as to distinguish between perceptions and actual impacts of tourism.

\section{Finding a balance - visually}

\subsection{Finding a balance}

The goal of any kind of sustainable development project is finding an optimal way of fulfilling all requirements of the concept. The maximisation of one or two leads to an unbalanced way of development which might be sustainable regarding these parameters but not the rest.

However, ecological aspects often gain priority within the concept. When the susceptibility of the physical environment represents an obstacle to the development of a viable tourism sector, sustainable tourism development cannot be the case. Environmental issues are continuous focal points of activity at resort and hotel developments, particularly when the development is situated entirely or partly in a natural setting. The impact of these either they are found at the edge of a natural area/national park or at areas of particularly hard risks tend to be more significant.

A major study of resident perceptions on the impact of tourism on natural environments in Hawaii, North Wales and Turkey carried out by Liu et al. [9] showed the highest priority given to the protection of the environment for planning purposes. It was ranked higher than cultural benefits, social cots and even economic benefits.

Thus, regarding environmental impacts, there is usually an obvious imbalance observed in many respects. First of all, negative impacts of tourism on the environment have been discussed in more details than positive. Also, social and economic aspects of tourism development projects are often disregarded to environmental ones [6]. Taken environment as whole, appreciation of the complexity of the environment as a system is often lacking.

Local circumstances may support that certain environmental aspects gain higher priority of importance. Moreover, what is a well-recognised and significant impact in one region or type of environment may not be a problem elsewhere. 
For destination management to be sustainable it needs to address all the economic, social and environmental issues of that particular area. A number of methodologies have been put forward in an attempt to ensure that tourism activity is carried out in a sustainable way. Briefly, tourism development is sustainable only when none of the core components are neglected to others.

Theories and management methods of sustainable tourism development and life-quality improvement must be applied to all types of tourism and destinations. In order to secure long-term sustainability, the accordance amongst these is indispensable. Monitoring survey and analysis of various indicators assumes the existence of a complex, long-term approach, of which primary aim is the establishment of sustainable welfare as shown in figure 2.

\section{ECONOMIC INDICATORS SOCIAL INDICATORS}

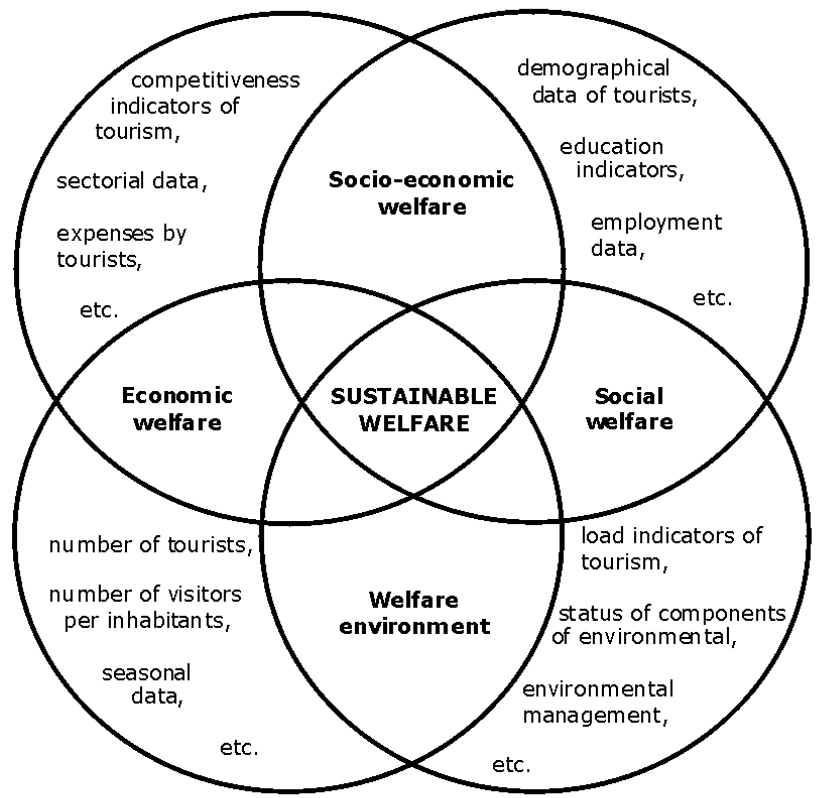

STATISTICAL INDICATORS

ENVIRONMENTAL INDICATORS

Figure 2: The system of sustainable development, tourism indicators and life quality.

\subsection{Adding visualisation}

\subsubsection{Applying the Sustainability Value Map}

In order to select an adequate method of integrated approach of planning, a useful tool would be the Sustainability Value Map (SVM), developed by Chris Butters, originally for buildings and urban development projects, although it can 
also be applied to the evaluation of any other sustainable products. The SVM visualises the three core elements of sustainability and the degree of what any product fulfils its goal.

A summary of the main features of SVM [10] is as follows. For each of the three main areas, eight parameters are defined, thus a product is benchmarked by 24 parameters in a complex way. The scale is set from 0 to 5 where 5 means what is seen as fully sustainable today. The values are scaled so that the outer rim, corresponding to a "horizon" of full sustainability, is clearly shown to be off.

The selection of parameters is, though provisional, systematic. Considering that sustainability is a dynamic process, the model can be used in relation to time, to assess how the sustainability of the product develops from year to year. Also, by applying the same indicators, it can be a tool for comparing different projects.

However, as pointed out earlier in this paper, impacts my vary locally, it is important to bear it in mind that the indicators used can and should vary to some extent depending on local conditions and on project scale. Also, as some of the components are rather complex, for a full assessment most will need a more detailed breakdown.

Applying the Value Map for tourism development projects may be relevant from the point of view of key elements often associated with sustainable tourism, i.e. preservation of the current resource basis for future generations, maintaining the productivity of the resource basis, maintaining biodiversity and avoiding irreversible environmental changes.

In its simplified form, it provides a checklist and framework for designers, and for discussion amongst participants in a planning process. In its detailed form, ideally, it gives a complete qualitative and quantitative picture of the condition of a project [10].

Visualisation is further promoted by having the mean value of indicators all three areas calculated, and also added to the original version of SVM.

\subsubsection{Selecting the right set of indicators}

As pointed out by Newsome and Moore [9], the degree and extent of any negative impacts, however, will depend on where the development is located, building design and adaptation to existing natural conditions, waste treatment systems, recycling and pattern of resource consumption as well as approaches to the recreational activities that take place in association with the development.

Due to both the great variety of tourism activities and that of the local endowments, questions may be raised on the relevance and general applicability of a given indicator. One might be used restricted only for certain local or regional issues. Furthermore, there is a necessity to distinguish qualitative and quantitative parameters; and finally two more questions are raised as (a) whether the selected indicator can be quantified, and (b) selecting the right set of indicators is possible at all [11].

For the latter one, an integrated approach of planning is required that takes the project scale and local endowments and the variables created on the basis of 
these into consideration. In a full assessment most variables also need a more detailed breakdown.

\subsubsection{Examples}

As a first step, the SVM is used to evaluate the environmental aspects of tourism development. Taken as an example, environmental impacts of a fictitious hotel development are discussed hereby and the SVM is applied in figure 3.

The average conditions of the receiving environment are well-indicated in the figure and can be marked as 'average' (with a sustainability value of 3.125 ). It can also be seen, however, that waste management, being a major issue elsewhere too, is the main problem source. Due to the large amount of volumes proceeded (average tourists tend to produce more waste than local people), the low application level of recycling, waste prevention strategies and the nature of the receiving environment here, it is an unsolved problem. Thus, the value given is well below that of other indicators as shown in table 1 .

On the other hand, demands for further development in fields such as noise prevention or soil prevention can now be held back as probably adequate measures have already been to taken to fulfil these goals.

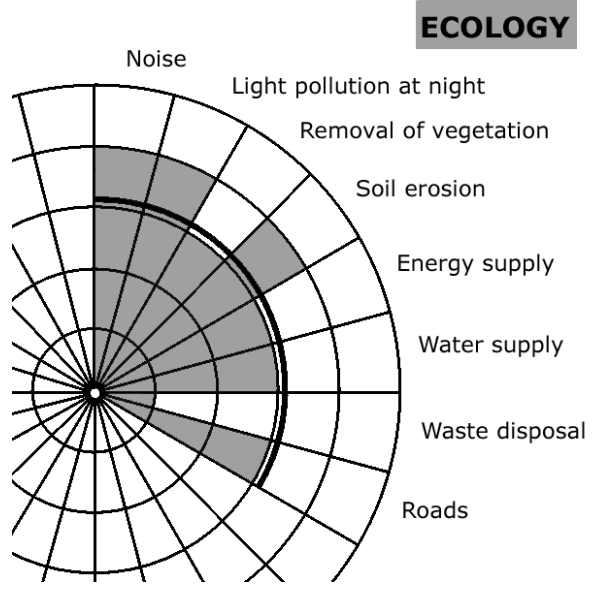

Figure 3: Environmental impacts of infrastructure and support facilities in the development of tourism.

For the evaluation, the most determinant environmental factors applied are indicated in table 1.

As a next step, the relationship of the three core elements is shown in figure 4. Here, a development project is visualised where environment seems to be managed in a more or less sustainable way thus is in a generally good conditions indicated by its average sustainability value of 4 .

Key issues of discussing sustainable development projects are about this average. Renewable energy sources (RES) seem to be one of the keystones of discussion. A survey carried out among tourist operators in Queensland, 
Australia [12] indicated positive interest in installing RES for their operation, and this is of fundamental importance to the viability of future strategies for increasing RES uptake. It is especially large hotels that tend to be affirmative on this issue may be due to their perceived market pressure to be 'Green'. Also, according to Edgar's [13] observation, they are more likely to consider marketing of environmental initiative as an important component for overall business strategy. However, opinions on the marketing value of RES within the tourism industry are rather mixed.

Table 1: Environmental impacts of infrastructure and support facilities in the development of tourism, derived from Newsome and Moore [6].

\begin{tabular}{|c|c|c|}
\hline Activity & Possible impact & $\begin{array}{l}\text { Sust. } \\
\text { value }\end{array}$ \\
\hline \multicolumn{3}{|l|}{ Land clearing } \\
\hline Noise & Disturbance to wildlife & 4 \\
\hline Light pollution at night & Disturbance to wildlife & 4 \\
\hline Removal of vegetation & $\begin{array}{l}\text { Loss of habitats } \\
\text { Shift in species composition of area } \\
\text { Smaller population of plants and animals } \\
\text { Weed invasion } \\
\text { Increased fragmentation of habitats }\end{array}$ & 3 \\
\hline Soil erosion & $\begin{array}{l}\text { Soil loss } \\
\text { Stream sedimentation and reduced water quality }\end{array}$ & 4 \\
\hline Energy supply & $\begin{array}{l}\text { Noise from generators } \\
\text { Pollution from fumes and oil/reduced air quality } \\
\text { Disturbance corridors }\end{array}$ & 3 \\
\hline Water supply & $\begin{array}{l}\text { Disturbance corridors } \\
\text { Ground water abstraction/reduced water tables } \\
\text { Construction of dams/disrupted stream flow }\end{array}$ & 3 \\
\hline Waste disposal & $\begin{array}{l}\text { Need for solid landfill or removal of waste off-site } \\
\text { Liquid treatment facilities/odour, litter }\end{array}$ & 1 \\
\hline \multicolumn{3}{|l|}{$\begin{array}{l}\text { Transportation } \\
\text { infrastructure }\end{array}$} \\
\hline Roads & $\begin{array}{l}\text { Nutrient, fertiliser, pesticide and oil run-off } \\
\text { Road corridor impacts and noise from vehicles } \\
\text { Barriers to animal movement }\end{array}$ & 3 \\
\hline
\end{tabular}

In cases, when the goals of sustainability are neither accomplishable from the point of view of the society nor reasonable from the point of view of the economy, these issues must receive more attention. At this stage, this development does not meet the demand of the local population at all. Without public involvement and the support of the local economy by fundamental financing for infrastructure among others, the outcome of this project is rather doubtful. From the point of view of tourists, it can be considered to be on a somewhat average level. In the one hand, certain aspects (accessibility) indicate a higher level of development whereas on the other, most of the components (aesthetics, security, variety) are just average. 


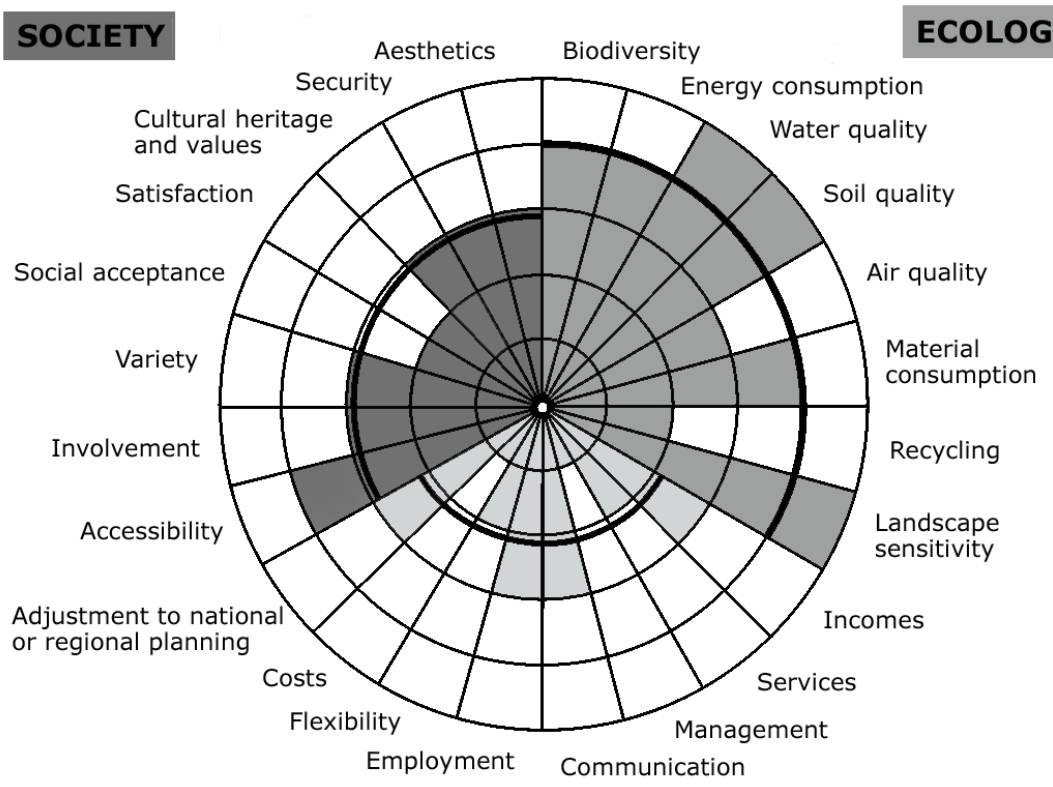

ECONOMY

Figure 4: An example of the Sustainability Value Map applied for tourism development projects.

\section{Conclusions}

The topic of sustainable tourism is still an evolutionary paradigm that is seen as a goal to be achieved for small-scale development in the supply environment and research enhancement on the niche characteristics in the demand and supply sides of the tourism system.

A sustainable planning approach includes the integration of economic, environmental and socio-cultural values (i.e. holistic planning), also having it integrated to other planning processes as well as preservation of essential ecological processes.

With its complexity, Sustainable Value Map provides a possibility to the advancement of sustainable tourism development. However, in order to achieve this, it has to undergo further research with several case studies of all branches of the tourism sector.

\section{Acknowledgements}

The authors acknowledge Chris Butters for permitting the use of the Sustainability Value Map for this research purpose. For further details, please contact chris@butters.no or the authors. 


\section{References}

[1] Holden, A., Environment and Tourism, Routledge Introduction to Environment Series, Routledge: London and New York, 225p, 2000.

[2] Burton, R., Travel Geography, Longman, 514p, 1995.

[3] Rátz, T., The role of climatic and weather factors in influencing travel behaviour (in Hungarian), Turizmus Bulletin, 10, special edition, pp. 4253, 2006.

[4] Dávid, L., Baros, Z. \& Szilágyi, Zs., Dimensions and environmental problems of sport tourism (in Hungarian), Tájökológiai Lapok, 4(2), pp. 395-405, 2006.

[5] Hall, C. M. \& Lew, A. A., (eds.), Sustainable Tourism: A Geographical Perspective, Addison Wesley Longman: Essex, pp!!! 1998.

[6] Newsome, D. \& Moore, S. A., Natural Area Tourism, Aspects of Tourism 4., Channel View Publications: Clevedon, England, 340p, 2002.

[7] Mathieson, A. \& Wall, G., Tourism: Economic, Physical and Social Impacts, Longman: London, pp!!! 1982.

[8] Ahmad, A., Environmental impact assessment in the Himalayas: An ecosystem approach, Ambio, 22(1), pp. 4-9, 1993.

[9] Liu, J.C., Sheldon, P. J. \& Var, T., Resident perception of the environmental impacts of tourism, Annals of Tourism Research 14(1), pp. 17-37, 1987.

[10] Urban Ecology: Projects in Europe - visions for Oslo?; Oslo kommune Havnevesenet. http://www.arkitektur.no/files/file46226_urban_ecology. pdf

[11] Puczkó, L. \& Rátz, T., Impacts of Tourism (An Introduction), Häme Polytechnic: Finland, 408p, 2002.

[12] Dalton, G. J., Lockington, D. A. \& Baldock, T. E., A survey of tourist operator attitudes to renewable energy supply in Queensland, Australia, Renewable Energy, 32, pp. 567-586, 2007.

[13] Yielding, E. D., Giants versus minnows, is there a difference? Progress in Tourism and Hospitality Research. 4(3), 255-265, 1999. 